\title{
Temperature Coagulant Tub Variation Effect on the Characteristic of Hollow Fiber Dialyser from Cellulose Acetate Composite D-Glucose Monohydrate
}

\author{
Rizki Firsta Wahyuliswari ${ }^{1}$, Siswanto $^{2}$, Prihartini Widiyanti ${ }^{13^{*}}$ \\ ${ }^{1}$ Biomedical Engineering Study Program, Faculty of Science and Technology, \\ Universitas Airlangga, Indonesia \\ ${ }^{2}$ Physics Study Program, Faculty of Science and Technology, \\ Universitas Airlangga, Surabaya, Indonesia \\ ${ }^{3}$ Institute of Tropical Disease, Universitas Airlangga, Indonesia \\ *Corresponding author: siswanto_fst@yahoo.co.id, pwidiyanti@fst.unair.ac.id
}

Keywords: cellulose acetate, D-glucose monohydrate, hollow fiber, dialyzer membrane, spinning

\begin{abstract}
Polysulfone is synthetic polymer widely used as basic material for dialyzer membrane. Cellulose acetate is non-synthetic, hydrophilic polymer which has low tendency of fouling and has good thermal stability and permeability so it is considered as alternative material for hollow fiber dialyzer. A proper hollow fiber can be achieved by setting a proper temperature of coagulation bath along the spinning process. This research aims to understand the effect of coagulation bath temperature variations on the physical characteristic such as pore size, tensile strength, swelling rate and creatinine clearance of cellulose acetate - D-glucose monohydrate hollow fibers. Hollow fibers were fabricated using spinneret at temperature variations $5^{\circ} \mathrm{C}, 10^{\circ} \mathrm{C}, 15^{\circ} \mathrm{C}$ dan $20^{\circ} \mathrm{C}$. Physical characteristics were estimated by doing morphology test using SEM, tensile test, swelling test towards Simulated Body Fluid (SBF) and filtration test towards creatinine. Result revealed that the hollow fibers from $5^{\circ} \mathrm{C}$ coagulation bath temperature gives the best characteristic and performance with tensile strength $27,421 \mathrm{~N} \mathrm{~mm}^{-2}$, pore size $0,0295-0,0858 \mathrm{~nm}$, swelling rate $4,18 \%$, elongation rate $4,4 \%$, flux rate $1,6032-1,7956 \mathrm{~mL} \mathrm{~cm}^{-2} \mathrm{~min}^{-1}$ and creatinine clearance rate $40,14-48,30 \%$. It is potential to be applied as dialyzer membrane.
\end{abstract}

\section{Introduction}

Kidney failure is a clinical condition marked by the decrease of kidney function in the form of glomerulus damage. That condition makes a kidney fail to filter the toxic metabolism feces. Generally, a kidney failure patient will be treated by giving both an artificial kidney (hemodialysis) therapy and kidney transplantation [1]. A hemodialysis therapy machine consists of 3 compartments, namely blood compartment, dialysate compartment, and artificial kidney (dialyser) compartment. Blood purification process (hemodialysis) takes place in dialysers [2].

At the moment, hemodialysis therapy generally uses dialysers membrane in the form of hollow fiber. Dialysis membrane in the form of hollow fiber is assumed to be able to widen the width of membrane surface connected with the blood if it is compared with the use of flat membrane. The effect is the increase of membrane ability to filter [1]. Hollow fiber is able to minimize fouling when the filtration is processing because blood is horizontally flowed, different from the flat membrane which vertically flows blood [3].

Dialyser membrane is a semipermeable membrane used in the hemodialisis process. Membrane characteristics which is essential and influence membrane function as dialiser are size pore, the surface area, membrane thickness, pore density and protein absorption [4]. Dialyser membrane can be produced by natural-basic polymer materials such as either cellulose acetate or synthetic polymer such as polysulfone. As most-used polymer in producing dialysis membrane, polysulfone still has some weaknesses, that is higher tendency of fouling than the hydrophilic membrane [5]. Polysulfone also has lower biocompatibility if it is parallelized with natural-based polymer membrane [6]. On the other hand, cellulose acetate membrane is applied so many times on a bioseparation system process to have ultra filtration and nano filtration process and osmosis 
reverse. This is caused by the state of cellulose acetate that has thin size $(6-5 \pi \mathrm{m})$, symmetrical membrane structure, and pore size that supports good water permeability; it could also separate medium size of molecule such as creatinine and urea [5]. Cellulose acetate also has fouling endurance due to the excellent hidrophylicity level, and it has excellent thermal stability as well [6].

This research focused on the dialysers membrane in form of hollow fiber which has cellulose acetate material. This cellulose acetate hollow fiber production is added with non-solvent D-glucose monohydrate substance because it gives a good result on the increase of filterable membrane [6]. In this research, researchers made a variation of coagulant bath temperature to compare the result of characterization consisting of morphology test, tensile strength test, and filtration test to explore hollow fiber work in passing creatinine.

Kidney failure is a clinical condition marked by the decrease of kidney's function that can be either temporary or permanent. It begins with the damage on glomerulus which has effects on the kidney that is not able to perform filtration process of toxic metabolism product [1]. Chronic kidney disease diagnosis is taken if the glomerulus filtration rate value is less than $60 \mathrm{ml} / \mathrm{minute} / 1,73 \mathrm{~m}^{2}$ [7]. Creatinine released from skeleton muscle is constantly used as a standard of Glomerular Filtration Rate (GFR) measurement because the creatinine is filtered freely and is not reabsorbed. Due to that case, creatinine concentration in urine also becomes standard of chronic kidney failure diagnosis [8].

Cellulose acetate membrane is asymmetrical membrane derived from cellulose acetate polymer. The main characteristic of cellulose acetate is symmetric membrane structure, and pore size that supports excellent water permeability. Cellulose acetate can separate the medium size molecules as well as creatinine and urea [3]. Cellulose acetate has endurance on fouling due to its excellent hydrophilicity, and it also has excellent thermal stability [5]. The addition of D-Glucose monohydrate as an additional non solvent substance could act an important role on membrane diffusion process. It alter the membrane pore quality improvement in order to increase membrane filtration ability [5].

Research done to develop efficiency the process dialysis, not only dialysis system but also the properties of membrane dialyser which used. Other research had done using cellulose acetate as dialyser membrane in flat sheet [5]. By the use of formic acid as solvent and add non-solvent dglucosa monohydrate. This research result indicates that the higher concentration of d- glucosa monohydrate, improve the ability of the inner membrane in urea filtration until $49,77 \%$ and creatinine filtration until $19,54 \%$.

In the hollow fiber process, there are several factors that affect the formation and membrane pores evolution are coagulant tub distance, the spinning temperature and coagulant tub temperature.A coagulant tub temperature could affect the asymmetrical structure of the membran pores because the relation with duration of poreformation. At the time dope solution put in coagulant tub then diffusion process of smooth pore happened and formed asymmetrical membrane. Asymmetrical membrane pore are the condition of the pore where inner smaller than outside .Asymmetrical membrane is the most widely used membrane because it has higher flux compare with symmetrical [9].

The use of hollow fiber as a dialysis membrane can enlarge the width of membrane surface connected with the blood so that the flux rate or the ability to filtrate could be larger [1]. Some elements that determine the potential and application of hollow fiber are pore size, membrane width and morphology substructure [7].

Hollow fiber membrane has been much used in the biomedical application, especially for filtering blood which is in hemodialysis, hemofiltration and blood oxygenation. Hollow fiber is cyllindrical solid fiber with hollow in the middle part as the place where blood flow happened. The use of a hollow fiber as of a membrane dialysis capable to enlarge the membrane surface area which has blood contact. This phenomena could increase flux or filtration ability [8]. Hollow fiber membrane is more chosen compared to the flat membrane because many weaknesses of flat ones. The flat membrane often occurs fouling and it would made membrane performance reduced. While performance hollow fiber membrane is higher because it has broad area in every unit of volume. It 
is more effective for the process of separation. The surface area would make hollow fiber have mass $3000 \mathrm{~m}^{2} / \mathrm{m}^{3}$ than flat one only $400 \mathrm{~m}^{2} / \mathrm{m}^{3}$ [9].

Based on the background, this research aimed to be directed to making membrane dialiser shaped a hollow fiber made cellulose acetate that dissolved in formic acid because the price far more affordable compared to polisulfon, but it has adequate specification and characteristic todevelop dialyser membrane. d-Glucose monohidrate play role in optimizing power of filtration membrane [6]. In this research, we used the temperature variation of coagulant tub size pore to get the appropriate pore size, proper mechanical properties and optimal filtration capability to creatinin, and to explore the temperature of coagulant tub in yielding hollow fiber with the best filtration speed to creatinin ( $\mathrm{ml} /$ minute). This proper speed would quickening hemodialisa therapy. Characterization of thos dialyser membran including tensile strength, morphology assay, filtration test and swelling test.

\section{Materials and Methods}

\subsection{Materials}

The material used in this research was cellulose acetate (Sigma Aldrich), format acid, D-glucose monohydrate (Sigma Aldrich), aquades, creatinine. In this research, the method used to create hollow fiber was spinning method using spinneret.

\subsection{Methods}

\subsubsection{Synthesis}

The preparation is started by weighing each material on the composition measurement of $20 \% \mathrm{wt}$ cellulose acetate, $10 \% \mathrm{wt} \mathrm{D}$-glucose monohydrate and format acid inasmuch as $70 \% \mathrm{wt}$. Each material, that had already been measured, was dissolved by using stirrer to make a dope solution. Dope solution was created by fusing cellulose acetate powder little by little into format acid and then D-glucose monohydrate was added little by little and stirred until the homogeny appeared, which took time more or less 1-2 hours. The next step was to let dope solution stay inside beaker glass and let it closed tightly with wrap plastic for about 24 hours to remove the got-in air bubble during the stirring process.

The forming process of hollow fiber can be done with a spinneret with aquades as a coagulant. Coagulation bath temperature variation can be done on four temperature points those are $5^{\circ} \mathrm{C}, 10^{\circ} \mathrm{C}$, $15^{\circ} \mathrm{C}, 20^{\circ} \mathrm{C}$. The forming process started from pouring down dope solution on receptacle pipe. It was then given the pressure from the compressor to push out the dope flow to the spinneret pin and then flow to coagulant bath. Dope solution that came out of spinneret pin was coagulanted in coagulation bath in the form of hollow fiber. It stayed in for about 1 hour to assure that the whole solution was coagulated or turned into solid. Next, the hollow fiber was heated in the oven for 10 minutes in $50^{\circ} \mathrm{C}-60^{\circ} \mathrm{C}$ to steam and remove the waste of format acid.

\subsubsection{Morphology Test}

Hollow fiber sample membrane need to be cleared first and dried before placed on sample holder. Sample holder size was $12 \mathrm{~mm}$ or $25 \mathrm{~mm}$. Samples then are sputtered with Au or Pd. Double-sided tape conductive is required to affix sample. Broad contact sample area will be favorable for samples identification. Scanning Electron Microscopy (SEM) would produce image that could were analysed the intensity of light formed from samples being tested. Pore size could be measured from the SEM image.

\subsubsection{Tensile Strength Test}

The sample is shaped like a rectangle with each end of the wider. Before the sample is placed on the tensile machine, thick membrane is measured first. Measurement of the thickness of the membrane is made at some point for the average values were taken. Then the samples are placed at each of the test before the machine is turned on and the load drawer units mounted on Newton. After that, the sample is drawn with a certain speed to break up. Towing load value and samples length alteration at the time broke are recorded. The results were the tensile strength value and elongation of the tested materials. 


\subsubsection{Filtration Test}

Creatinin solution was prepared before making equal concentration to creatinin value around $2,5 \mathrm{mg} / \mathrm{dl}$. Then creatinin solution was distributed parallely with hollow fiber membrane and produce permeat (filtrat and retentat ( solution after filtrated ). Then it could be performed the filtration of SBF solution-creatinine. Each hollow fiber sample tested with the cross-flow system. Flux value calculated based on equation $\mathrm{J}=\mathrm{V} / \mathrm{A} . \mathrm{t}$, where $\mathrm{j}$ are a flux $\left(\mathrm{L} \cdot \mathrm{m}^{-2}\right), \mathrm{t}$ is time in the day, $\mathrm{V}$ is permeat volume $(\mathrm{L})$ and $\mathrm{A}$ constitutes extensive the membrane surfaces $\left(\mathrm{m}^{2}\right)$. And calculated also duration time of hollow fiber in filtering solution that is by counting how much volume filtered out every minute of it ( $\mathrm{ml} / \mathrm{second})$. After having acquired filtered out solution, solution concentration would be measured using turbidimeter to know the rejection value of hollow fiber to creatinin. Rejection value measurement gained by measuring creatinin concentration before and after passing membrane using turbidimeter. The data could be calculated based on the equation $\mathrm{R}=\left(1-\mathrm{C}_{\mathrm{p}} / \mathrm{C}_{\mathrm{f}}\right) \times 100 \%$ where $\mathrm{R}$ is coefficient rejection, $\mathrm{Cp}$ is solute concentration in permeat and $\mathrm{Cf}$ is solute concentration in feed.

\section{Result and Discussion}

\subsection{Morphology Test}

Morphology test was done by using Scanning Electron Microscope (SEM). Morphology test produced data about surface pore size in inside part of hollow fiber's wall. There are two color degradations which are dark and light indicating hollow fiber wall structure. Light color on SEM result Figure indicated higher surface than that of the dark, so it can be suggested that dark surface is hollow fiber's inside wall pore. The analysis result of the formed pore on hollow fiber is different in each temperature variation, as shown in Table 1.

Table 1. Hollow Fiber Cellulose Acetate - D-glucose Monohydrate Pore Size Data

\begin{tabular}{|c|c|}
\hline Temperature $\left({ }^{\mathbf{0}} \mathbf{C}\right)$ & Pore Size $(\boldsymbol{\mu m})$ \\
\hline 5 & $0,029-0,086$ \\
\hline 10 & $0,095-0,170$ \\
\hline 15 & $0,170-0,229$ \\
\hline 20 & $0,166-0,297$ \\
\hline Ultra filtration Membrane $[\mathbf{1 0}]$ & $\mathbf{0 , 0 0 1}-\mathbf{0 , 1} \boldsymbol{\mu m}$ \\
\hline
\end{tabular}

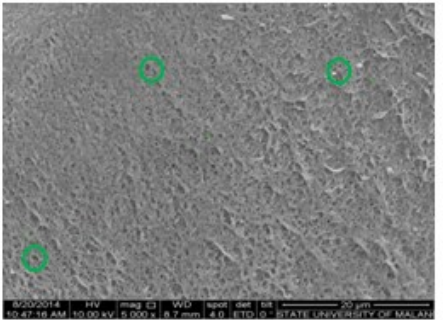

(a)

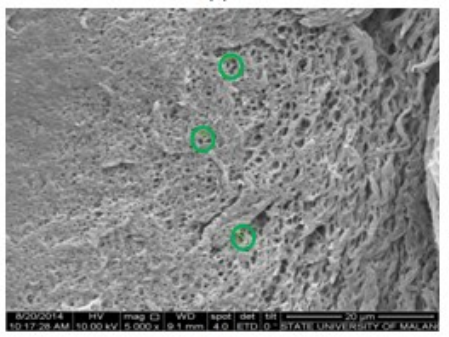

(c)

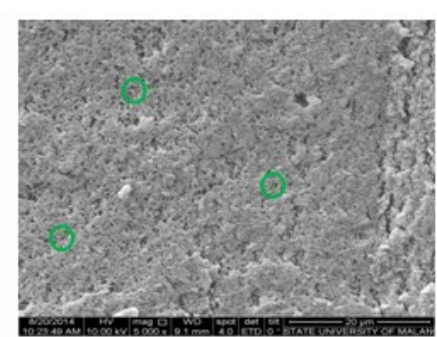

(b)

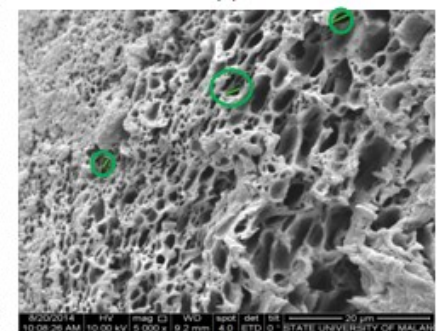

(d)

Figure 1. The Image Result of SEM Wall Surface In Hollow Fiber Cellulose Acetate $D$-Glucose Monohydrate with Temperature Variation $5^{\circ} \mathrm{C}(\mathrm{a}), 10^{\circ} \mathrm{C}(\mathrm{b}), 15^{\circ} \mathrm{C}(\mathrm{c})$ and $20^{\circ} \mathrm{C}(\mathrm{d})$ 
The usable pore size in hemodialysis is ultra filtration pore size that is $0,001-0,1 \mu \mathrm{m}[10]$. Hollow fiber morphology test result shows that the hollow fiber pore size which is suitable and proper to be categorized as ultra filtration membrane can be found on the temperature of $5^{\circ} \mathrm{C}$ variation which has $0,0295-0,0858 \mu \mathrm{m}$ pore size range. Ultra filtration pore size would make hollow fiber membrane able to pass creatinine metabolism remnant substance which has $\pm 0,06 \mu \mathrm{m}$ diameter. The difference of coagulation bath temperature could affect the pore form because the diffusion process goes slowly when dope solution comes into coagulation bath. The lower the coagulation bath temperature, the slower the diffusion process become, so that the molecule of hollow fiber creator biopolymer turns tighter and produces tighter pore form [11].

From morphology test result, it provide information about form and size of outside and inside diameter data in hollow fiber. This research use spinneret which usually used to make hollow fiber but there is a difference in each of its result, as shown on Table 2 and Figure 2. This diameter size difference is affected by coagulation bath temperature that causes the difference of solubility time of dope solution. The lower coagulation bath temperature is, the sooner the dope solution settingtime, so it may lessen the probability of solution overflowing and enlarges the diameter size [11].

Table 2. The Size Data of Outside Diameter (D) and Inside Diameter (d) of Hollow Fiber Cellulose Acetate - D-Glukosa Monohydrate

\begin{tabular}{|c|c|c|}
\hline Temperature $\left({ }^{\circ} \mathbf{C}\right)$ & $\mathbf{D}(\mathbf{m m})$ & $\mathbf{d}(\mathbf{m m})$ \\
\hline 5 & 1,513 & 0,8772 \\
\hline 10 & 1,788 & 0,782 \\
\hline 15 & 2,027 & 0,7052 \\
\hline 20 & 2,344 & 0,4626 \\
\hline $\begin{array}{c}\text { Dialyzer PS-2100L Kawaisumi Laboratories } \\
\text { Inc. }\end{array}$ & $\mathbf{0 , 2 4 - \mathbf { 0 , 2 4 5 }}$ & $\mathbf{0 , 2}$ \\
\hline
\end{tabular}

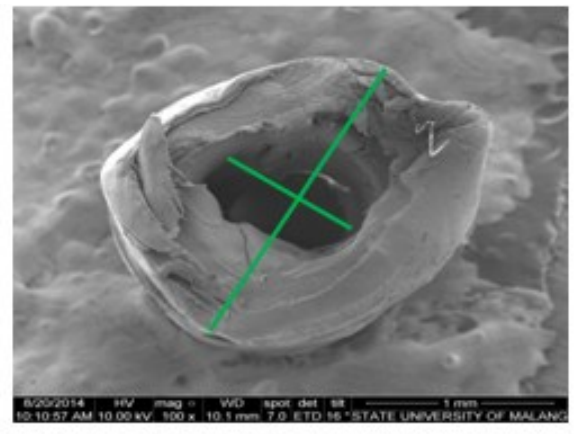

(a)

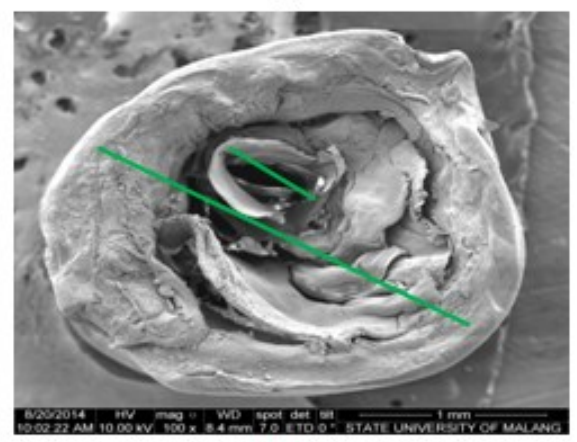

(c)

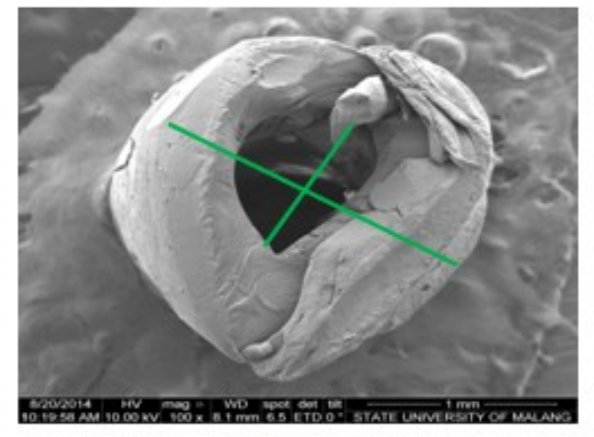

(b)

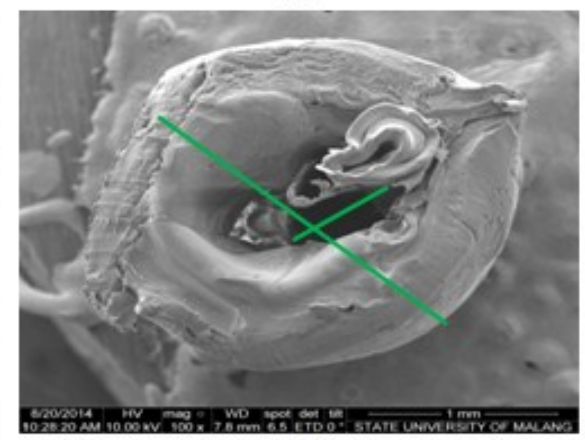

(d)

Figure 2. Image Result of SEM Form and Size of Hollow Fiber

Cellulose Acetate Diameter- D-Glucose Monohydrate with Temperature Variation of $5^{\circ} \mathrm{C}(\mathrm{a})$, $10^{\circ} \mathrm{C}(\mathrm{b}), 15^{\circ} \mathrm{C}$ (c) and $20^{\circ} \mathrm{C}(\mathrm{d})$ 


\subsection{Tensile Strength Test}

Membrane drawing power measurement can be done by using the autograph tool to explore hollow fiber mechanical thing in each temperature variation with the analysis of tensile strength rate and elongation. This test results in data of $\mathrm{F}$ (force). Diameter width (A) states that membrane can be counted from the difference of hollow fiber outside and inside diameter width. The affordable data can be analyzed so it could be known that the tensile strength rate uses the pattern of $\sigma=\mathrm{F} / \mathrm{A}$. Tensile strength rate of membrane to coagulation bath temperature variation graphic data is shown in Figure 3.

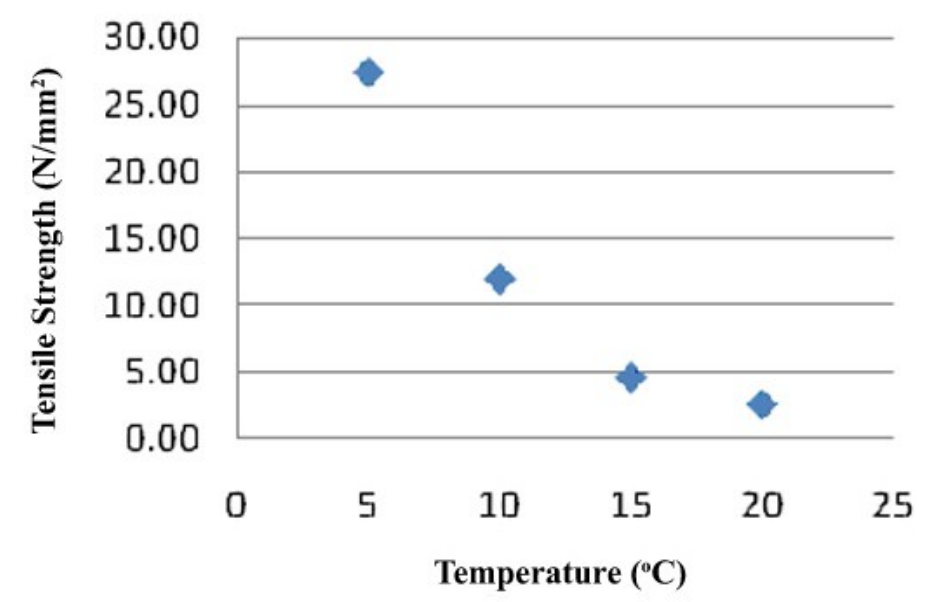

\section{Figure 3. Cellulose Acetate Hollow Fiber Tensile Strength Graphic-Monohydrate D-Glukosa to Coagulation Bath Temperature Variation}

Coagulation bath temperature variation used to create hollow fiber gives an influence on surface structure and hollow fiber pore size. The lower the coagulation bath temperature, the tighter the molecule distance is on hollow fiber. It makes the smaller and tighter formed-pore. Tight pore structure on formed hollow fiber will increase the membrane stretch which means that it will require greater strength to deform membrane. It means that it will have greater tensile strength on membrane. The highest tensile strength of hollow fiber with coagulation bath temperature variation on $5^{\circ} \mathrm{C}$ is $27,4 \mathrm{~N} \mathrm{~mm}^{-2}$. Meanwhile hollow fiber tensile strength rate for three temperature variations is in the range of hollow fiber tensile strength standard $23,1-33,8 \mathrm{~N} \mathrm{~mm}^{-2}$. The cellulose acetate could dispersed in composite, improve the binding and enhancing th mechanical properties [12].

\subsection{Filtration Test}

This filtration test was only done on $5^{\circ} \mathrm{C}$ hollow fiber temperature variation that shows the most optimal quality through the two previous tests. 7 hollow fibers with their $7 \mathrm{~cm}$ in length were arranged into a module and creatinine solution as a fodder solution was used. Creatinine solution used was a $2,5 \mathrm{mg} \mathrm{dL}^{-1}$ creatinine rate solution or its equal with creatinine rate on chronic kidney failure. Hollow fiber filtration test on creatinine solution was done by 4 times repetitions.

The turbidity of fodder solution and crossflow test result permeate were measured by turbid meter. Membrane selectivity appeared on rejection coefficient that is the ability of membrane in passing certain specification and in holding other specification. Rejection rate is counted by using the pattern of $\mathrm{R}=\left(1-\mathrm{C}_{\mathrm{p}} / \mathrm{C}_{\mathrm{f}}\right) \times 100 \%$ whereas $\mathrm{R}$ is a rejection coefficient, $\mathrm{C}_{\mathrm{p}}$ is a solubility substance concentrate in permeate (NTU) and $\mathrm{C}_{\mathrm{f}}$ is a solubility substance in fodder or feed (NTU). Measurement result data shows that hollow fiber rejection coefficient rate in average comes in $5^{\circ} \mathrm{C}$ temperature variation ranging in the rate of $40,14 \%-48,30 \%$ as shown on Table 4. 
Table 4. Hollow Fiber Turbidimetri Result Test Data ---- Cellulose Acetate - D-glucose Monohydrate

\begin{tabular}{|c|c|c|c|c|}
\hline Repetition & $\begin{array}{c}\text { Fodder Solution } \\
\text { Concentrate } \\
\text { (NTU) }\end{array}$ & $\begin{array}{c}\text { Permeate } \\
\text { Concentrate } \\
\text { (NTU) }\end{array}$ & $\begin{array}{c}\text { Rejection } \\
\text { Rate }\end{array}$ & $\begin{array}{c}\text { Creatinine } \\
\text { Rentetat Rate } \\
\text { (mg dL }\end{array}$ \\
\hline 1 & 1,47 & 0,77 & $47,62 \%$ & 1,19 \\
\hline 2 & 1,47 & 0,81 & $44,90 \%$ & 1,12 \\
\hline 3 & 1,47 & 0,76 & $48,30 \%$ & 1,21 \\
\hline 4 & 1,47 & 0,88 & $40,14 \%$ & 1,00 \\
\hline \multicolumn{4}{|c|}{ Normal creatinine Rate [13] } & $\mathbf{0 , 7}-\mathbf{1 , 2} \mathbf{~ m g ~ d L}^{-1}$ \\
\hline
\end{tabular}

Hollow fiber rejection rate on $5^{\circ} \mathrm{C}$ with its 4 times filtration test repetitions could showed the permeate giving remnants of creatinine rate based on blood normal creatinine standard range, which is $0,7-1,2 \mathrm{mg} \mathrm{dL}^{-1}$ [13]. The smaller the rejection rate, the bigger the hollow fiber ability is in passing the creatinine to be secreted from blood. The rejection rate of target molecules as well as protein binding/ total ratio of the molecule is important for selection suitable membrane [14].

\section{Conclusion}

- The lower the coagulant temperature in the use of spinning process $\left(5^{\circ} \mathrm{C}-20^{\circ} \mathrm{C}\right)$, the smaller and tighter the pore size formation is, and this is because of cellulose acetate solution diffusion D-glucose monohydrate.

- The hollow fiber tensile rate becomes higher as the coagulation bath temperature goes lower. It happens because there is a rise of membrane molecule tightness alongwith pore size which is getting smaller, so that membrane is difficult to deform.

- Hollow fiber cellulose acetate D-glucose monohydrate characteristic that has a potential to be applied as hemodialysis membrane candidate is on $5^{\circ} \mathrm{C}$ coagulation bath temperature variation. On this temperature, membrane will be produced with its pore size of 0,0295 $0,0858 \mathrm{~nm}$, tensile rate at $27,421 \mathrm{~N} / \mathrm{mm}^{2}$, and the creatinine rejection ability between 40,14 $48,30 \%$.

\section{Acknowledgement}

The author would like to thank to the Material Physic Laboratory, Chemistry Laboratory, Faculty of Science and Technology Universitas Airlangga, Pharmacy Faculty Universitas Airlangga and Sepuluh November Technology Institute for support in characterization.

\section{References}

[1] Sloane, Ethel, 2003. Anatomi dan Fisiologi untuk Pemula. EGC : Jakarta.

[2] Clark, W.R., Gao, Dayong. 2002. Properties of Membranes Used for Hemodialysis Therapy. Seminars in Dialysis-Vol 15 No 1 : pp.191-195.

[3] Peng, Na., Widjojo, N., Sukitpaneenit, P., May, T.M., Glen, L.G., et al. 2012. Evolution of Polimeric Hollow Fibers as Sustanaible Technologies: Past, Present and Future. Elsevier Science 1-7.

[4] Chelamcharla, Madhukar et.al. 2005. Dialyzer Membranes as Determinants of the Adequacy of Dialysis. Elsevier: Department of Medicine, University of Utah School of Medicine.

[5] Gautham, A., Javad, M., Manavalan, M., Najeeb, M.A., 2013. Hemodialysis Membranes: Past, Present and Future Trends, Int. Res. J. Pharm 4. 
[6] Idris, A., Hew K.Y., Chan M.K., 2009. Preparation of Cellulose Acetate Dialysis Membrane Using D-Glucose Monohydrate as Additive. Jurnal Teknologi, Universiti Teknologi Malaysia.

[7] Jafar, Tazeen H., Schmid, Christopher H., and Levey, Andrew S. 2005. Serum Creatinine as Marker of Kidney Function in South Asians: A Study of Reduced GFR in Adults in Pakistan. American Society of Nephrology.

[8] Ward, J., Robert, C., Roger, L. 2007. At a Glance Fisiologi, Terjemahan dr. Indah Retno Wardhani, Erlangga Medical Series.

[9] National Kidney Foundation, 2011. www.kidney.org.

[10] Qin, J.J., Wang, R., Chung, T.S., 2003. Investigation of Snear Stress Effect within A Spinneret Onflux, Separation and Thermomechanical Properties of Hollow Fiber Ultrafiltration Membranes, Journal of membranes Science 175.

[11] Annan K, 2012. Mathematical Modeling for Hollow Fiber Dialyzer: Blood and HCO-3 Dialysate

Flow Characteristics. International Journal of Pure and Applied Mathematics. Volume 79 No. 3 2012, 425-452

[12] Li S, Gao Y, Bai H, Zhang L, Qu P, Bai L, 2011. Preparation and Charcteristics of Polysulfone Dialysis Composite Membranes Modified with Nanocrystalline Cellulose. BioResources 6(2), 1670-1680.

[13] Aziz F, Witjaksono J, Rosjidi I, 2008. Panduan Pelayanan Medik. Model Interdisiplin Penatalaksanaan Kanker Serviks Dengan Gangguan Ginjal. EGC, Jakarta, p 32

[14] Suzuki H, Hirasawa H, 2010. Acute Blood Purification. Karger, Basel, Switzerland, p 103 